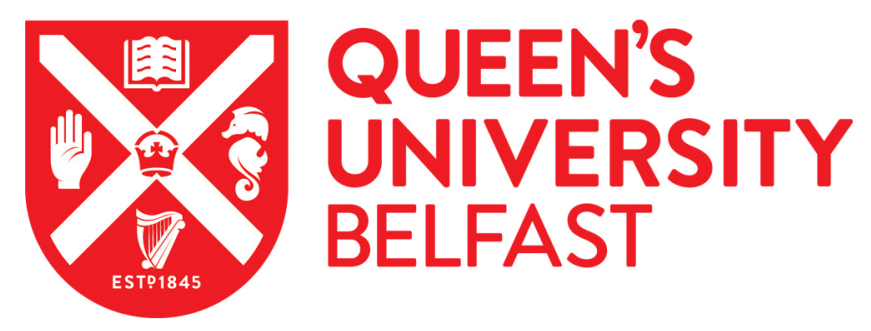

\title{
The influence of context and practitioner attitudes on implementation of person-centred assessment and support for family carers within palliative care
}

\section{Diffin, J., Ewing, G., Harvey, G., \& Grande, G. (2018). The influence of context and practitioner attitudes on} implementation of person-centred assessment and support for family carers within palliative care. Worldviews on Evidence-Based Nursing. https://doi.org/10.1111/wvn.12323

Published in:

Worldviews on Evidence-Based Nursing

\section{Document Version:}

Peer reviewed version

Queen's University Belfast - Research Portal:

Link to publication record in Queen's University Belfast Research Portal

\section{Publisher rights}

Copyright 2018 Wiley. This work is made available online in accordance with the publisher's policies. Please refer to any applicable terms of use of the publisher.

\section{General rights}

Copyright for the publications made accessible via the Queen's University Belfast Research Portal is retained by the author(s) and / or other copyright owners and it is a condition of accessing these publications that users recognise and abide by the legal requirements associated with these rights.

Take down policy

The Research Portal is Queen's institutional repository that provides access to Queen's research output. Every effort has been made to ensure that content in the Research Portal does not infringe any person's rights, or applicable UK laws. If you discover content in the Research Portal that you believe breaches copyright or violates any law, please contact openaccess@qub.ac.uk. 
THE INFLUENCE OF CONTEXT AND PRACTITIONER ATTITUDES ON IMPLEMENTATION OF PERSON-CENTRED ASSESSMENT AND SUPPORT FOR FAMILY CARERS WITHIN PALLIATIVE CARE

\title{
Short Title: Successful implementation of the CSNAT
}

\author{
Diffin $\mathbf{J}^{1,2}$, Ewing $\mathbf{G}^{3}$, Harvey $\mathbf{G}^{4,5}$, Grande $\mathbf{G}^{2}$ \\ ${ }^{1}$ School of Nursing and Midwifery, Queen's University Belfast, Belfast, Medical Biology \\ Centre, 97 Lisburn Road, Belfast BT9 7BL, UK \\ ${ }^{2}$ Division of Nursing, Midwifery and Social Work, University of Manchester, Jean \\ McFarlane Building, Oxford Road, Manchester M13 9PL, UK. \\ ${ }^{3}$ Centre for Family Research, University of Cambridge, Free School Lane, Cambridge CB2 \\ 3RQ, UK. \\ ${ }^{4}$ Health Management Group, Alliance Manchester Business School, University of \\ Manchester, Booth Street East, Manchester M13 9SS, UK. \\ ${ }^{5}$ Adelaide Nursing School, University of Adelaide, Adelaide Health and Medical Sciences \\ Building, North Terrace, Adelaide, Australia
}

- Corresponding Author: Dr Janet Diffin (Research Fellow), School of Nursing and Midwifery, Queen's University Belfast, Medical Biology Centre, 97 Lisburn Road, Belfast BT9 7BL, UK; Email: j.diffin@ qub.ac.uk; Phone: +44 (0)28 90972859

- Dr Gail Ewing (Senior Research Associate), ${ }^{3}$ Centre for Family Research, University of Cambridge, Free School Lane, Cambridge CB2 3RQ, UK; Email: ge200@ cam.ac.uk; Phone +44 (0)1223 334881 
- Professor Gill Harvey (Professor in Health Management); Health Management Group, Alliance Manchester Business School, University of Manchester, Booth Street East, Manchester M13 9SS, UK. Email: gill.harvey@manchester.ac.uk; Phone: +44 (0)161 8208344

- Professor Gunn Grande (Professor of Palliative Care); Division of Nursing, Midwifery and Social Work, University of Manchester, Jean McFarlane Building, Oxford Road, Manchester M13 9PL, UK. Email: gunn.grande@ manchester.ac.uk ; Phone: +44 (0)161306 7695

THE INFLUENCE OF CONTEXT AND PRACTITIONER ATTITUDES ON IMPLEMENTATION OF PERSON-CENTRED ASSESSMENT AND SUPPORT FOR FAMILY CARERS WITHIN PALLIATIVE CARE Short Title: Successful implementation of the CSNAT 
Background: The Carer Support Needs Assessment Tool (CSNAT) intervention is an evidence-based, person-centred approach to carer assessment and support within palliative care. As such, it requires a change in practice from a practitioner- to a carer-led assessment and support process. A paucity of studies have investigated factors affecting implementation of evidence based interventions within palliative care.

Objectives: To examine differences between high and low adopters of the CSNAT intervention in terms of practitioner attitudes to the intervention and organisational context. Methods: Phase IV study of implementation of the CSNAT intervention at scale in 36 UK palliative care services over six months. Survey at baseline and six months of practitioners at implementation sites, informed by the Promoting Action on Research Implementation in Health Services (PARIHS) Framework. Survey tools: (i) questionnaire to assess attitudes to the CSNAT intervention; (ii) Alberta Context Tool (ACT) to assess organisational context. Monthly data on intervention use enabled service classification as 'high' or 'low' adopters. Results: $157 / 462$ surveys returned at baseline; 69/462 at six months. Compared with 'low' adoption services, 'high' adopters were more likely to be hospice at home and day services; have a higher ratio of internal facilitators to total staff numbers; and higher scores for ACT ‘informal interactions' denoting more discussions about care between colleagues. Both had similarly positive attitudes to the CSNAT intervention pre-implementation, but by six months 'low' adoption services developed significantly more negative attitudes; while in 'high' adoption services attitudes mostly remained the same/improved.

Linking evidence to action: Implementation may be more successful for services that offer regular opportunities to use the intervention in practice, have sufficient levels of facilitators, stimulate more staff discussion, and encourage maintenance of positive motivation. Implementation of person-centred interventions needs to plan for such factors. This has informed an implementation toolkit for the CSNAT intervention. 
Accepted for Publication 17/05/18

Key words: End of life care, Intervention research, Terminal care/Palliative care/Hospice care, Evidence-based practice, Quantitative, Person-centred, carer 


\section{BACKGROUND}

Support provided by family carers is invaluable, enabling someone with a life-limiting illness to be cared for at home towards end-of-life (Grande, Addington-Hall \& Todd, 1998; Gomes \& Higginson 2006). Despite the rewards associated with being a family carer towards the end of life (Hudson 2004), negative impacts on family carers' physical and mental well-being have been reported (Aoun, Kristjanson, Currow et al., 2005; Schulz \& Beach, 1999; Stajduhar, Funk \& Outcalt 2013). Recent findings from Rowland, Hanratty, Pilling et al., (2017) highlighted the extensive time and money that family carers spend on providing endof-life care. It is therefore crucial that healthcare professionals support family carers systematically and holistically. Timely and tailored support for family carers at all stages of the caring trajectory will enable them to best care for the patient, and to maintain their own health and wellbeing.

The Carer Support Needs Assessment Tool (CSNAT) is a validated evidence-based tool which was developed to identify and address support needs of family carers within palliative care (Ewing, Brundle, Payne et al., 2013a; Ewing \& Grande, 2013b). For use in practice, the CSNAT intervention comprises (i) the comprehensive tool itself (CSNAT) integrated into (ii) a person-centred process of carer-led assessment, support and follow-up (The CSNAT Approach) (Ewing, Austin, Diffin et al., 2015) (Figure 1). Person-centred care involves a more collaborative approach between health professionals and service users, working in partnership 'with' people rather than doing 'to' them, and healthcare professionals taking a step back from being the 'expert' in care relationships (Collins, 2014). As such, using the CSNAT intervention involves a change in practice from a practitioner-led to a carer-led process of assessment and support, in line with government policy and national guidelines for carer assessment and support, and recommendations for person-centred practice (Department 
of Health (DoH) 2008; NHS Scotland 2008; DoH 2009; NICE, 2014; Ambitions for Palliative and End of life care, 2015). Research on the CSNAT intervention has shown it improves outcomes for carers (Grande, Austin, Ewing et al., 2017; Aoun, Grande, Howting et al., 2015b) is valued by carers (Aoun, Deas, Toye et al., 2015a), and that practitioners feel it has benefits for their practice (Ewing, Austin \& Grande, 2016).

Further understanding is now required on what enables wider scale implementation in real life practice, Phase IV of the Medical Research Council (MRC) guidance on implementing complex interventions (Craig, Dieppe, Macintyre et al., 2008; Moore, Audrey, Barker et al., 2015). This stage is often neglected in favour of the earlier stages of developing and testing of interventions, resulting in many evidence-based interventions not achieving their intended outcomes once implemented more widely. Crucially, implementation studies are particularly lacking in palliative/end-of-life care, despite recommendation of this stage of research in the recent Methods of Researching End of Life Care (MORECare) statement (Higginson, Evans, Grande et al., 2013).

Thus, we conducted a Phase IV study which implemented the CSNAT intervention at scale across different contexts within hospice/palliative care services. This Phase IV study is unique as it provides insight into implementation of a complex intervention for family carers rather than patients, and factors facilitating the shift to person-centred assessment and support. The full study had three main components: (1) Pre- and post- implementation surveys with individual practitioners, (2) Semi-structured interviews with practitioners with the role of 'internal facilitator' three and six months post implementation, and (3) focus groups with three services six months post-implementation. This paper reports on the first 
component of the study: the pre- and post-implementation survey with practitioners.

Qualitative data from components two and three are reported in a separate paper elsewhere.

\section{Theoretical Implementation Framework}

The Promoting Action on Research Implementation in Health Services (PARIHS) served as our guiding theoretical framework. PARIHS identifies three key components of the implementation process; evidence, context and facilitation (Kitson, Harvey \& McCormack, 1998; Rycroft-Malone, Kitson, Harvey et al., 2002). Implementation is more likely to occur when evidence is scientifically robust, aligns with practitioner and patient beliefs and local experience (high evidence), the context is receptive to change (high context), and there is appropriate input from internal and external facilitators (high facilitation) (Kitson, Harvey \& McCormack, 1998; Rycroft-Malone, Kitson, Harvey et al., 2002). Successful implementation is defined as a function of the complex interplay between evidence, context and facilitation. This paper reports quantitative findings relating to evidence and context. Facilitation, which evolved over time and lent itself to qualitative investigation, is reported in a separate paper.

The study objective was to examine differences between high and low adopters of the CSNAT intervention in terms of practitioner attitudes to the intervention and organisational context. 


\section{METHODS}

\section{Design}

Prospective quantitative pre- and post-implementation survey.

\section{Setting and implementation}

To achieve implementation at scale, study information was disseminated via conferences, eHospice articles, and email. UK palliative care organisations wanting to take part contacted the research team; thirty-six sites participated. Each site received the same training/support package from the research team (external facilitation): two to three practitioners from each site acted as internal facilitators (IFs). This formed the basis of the implementation strategy (See Supplemental File). Sites included day services, community clinical nurse specialist (CNS) teams, day hospices, social work teams and an outpatient clinic.

\section{Study sample}

Practitioners across all disciplines within each site, who were likely to use the CSNAT intervention in practice, were eligible.

\section{Survey administration}

Each site selected a member of staff to distribute hard copies of the survey packs to practitioners. This staff member also held the list linking study ID numbers/names to ensure that responses were anonymous, but that the researcher could track how many practitioners responded from each site.

Surveys were administered pre-implementation of the CSNAT intervention (baseline) and after six months. Surveys were returned directly to the research team using the pre-paid envelope provided. Their return was taken as consent to participate. 


\section{Data collection - individual practitioners: Survey instruments}

The 'Attitudes to implementation' (ATI) of the CSNAT intervention, designed for the study, and the Alberta Context Tool (ACT) (Estrabrooks, Squires, Cummings et al., 2009) was administered pre-implementation. Only the 'ATI' questionnaire was administered again at six months.

'ATI' questions were based on eight concepts which impact on implementation: acceptability, appropriateness, benefits, achievability, value, motivation, colleague support, and management support (Estrabrooks, Squires, Cummings et al., 2009; Rogers, 1995; Proctar, Silmere, Raghavan et al., 2011). Question format pre-implementation used the future tense, e.g. 'The CSNAT will be beneficial to my practice'. Post implementation it used the past tense, e.g 'The CSNAT was beneficial to my practice'. Questions referred both to individual practice and to the service, as CSNAT could be acceptable to a practitioner's individual practice, but not to their service, e.g. due to contextual restraints. A seven-point Likert scale ranging from 'strongly disagree' to 'strongly agree' was used with higher scores indicating greater agreement. The 'ATI' questionnaire was piloted with five practitioners previously involved in using the CSNAT intervention to ensure it was asking the intended questions, and that the format was comprehensible.

Data were also collected on practitioners' role, home visits, and previous use of an evidencebased tool.

The ACT is based on the 'context' component of PARIHS and measures concepts of organisational context potentially amenable to change (Estrabrooks, Squires, Cummings et 
al., 2009). The homecare version includes 56 items encompassing eight concepts: leadership, culture, evaluation, social capital, organisational slack (scoring - item means), formal interactions, informal interactions, and structural and electronic resources (counted to derive a final score). Higher scores indicate a stronger, more positive context. Scores can also be aggregated at service level. Scoring followed guidelines by Squires, Huthinson, Hayduk et al., (2014). Cronbach's alpha exceeds 0.70 for each of the ACT concepts (Squires, Hayduk, Huthinson et al., 2015); reliability analysis in the current study showed similar results.

\section{Data collection - each site}

\section{(1) Service descriptions}

Information was obtained from the lead internal facilitator on service type, number of new patients annually, number of staff in post, and number of staff who would be using the CSNAT intervention.

\section{(ii) Level of adoption of the CSNAT intervention}

‘Adoption' was defined as total number of carers who completed CSNAT intervention in relation to total number of new patients. Use of a proxy denominator was necessary because number of new carers was often not recorded. Therefore, each site was requested to return monthly data for six months on the number of new patients and use of the CSNAT intervention with their carers.

A measure of 'fidelity' of the CSNAT intervention, in relation to its stages of assessment and follow-up (Ewing, Austin, Diffin et al., 2015) was also obtained. Services were asked to supply data on the number of carers who indicated they had support needs and on the number of carers who had follow-up action plan completed with them. This data served as an 
indicator that the CSNAT intervention was being used as intended. All data were collected between November 2013 - September 2014.

\section{Statistical Analysis}

Services were defined as either 'high' or 'low' adopters using median level of adoption as a cut-off point ( $25 \%)$; all those below this value were classified as 'low' adopters and all those above were 'high' adopters. Seven recruited services failed to return the full six months of data on level of adoption of the CSNAT intervention. Thus, only 29/36 services returning the full six months data were included in the analyses as level of adoption of the CSNAT was the main outcome variable. Characteristics of practitioners within 'high' and 'low' adoption services who returned a baseline survey were described.

To examine differences in staff attitudes to the CSNAT intervention between 'high' and 'low' adoption services, 'ATI' questionnaire scores were aggregated for each service and mean values for 'high' and 'low' adopters calculated. Due to small sample size, a bootstrap technique was performed on the data and confidence intervals calculated (Scholz, 2007).

To examine changes in staff attitudes over time, changes in 'ATI' scores were assessed for individual practitioners within each group who returned the 'ATI' questionnaire at both timepoints, as use of aggregate scores to assess changes would be statistically inappropriate. We used a Wilcoxon signed rank test (due to non-normal distribution of data).

To examine representativeness of individuals responding at both time-points, differences in survey responses for those who responded at both time-points and those who responded at baseline only were compared using a Mann Whitney U-test (due to non-normal distribution 
of data). Chi-square was calculated to test for differences in categorical variables between the two groups and Fishers exact test was used if expected frequencies were less than five.

To examine service characteristics and organisational context of 'high' and 'low' adopters of the CSNAT intervention, descriptive statistics were calculated for service characteristics including service type, and number of new patients annually (as an indication of service size). Chi-square was calculated to test for differences between the two groups. ACT survey scores at baseline were aggregated for each service and mean score calculated for 'high' and 'low' adoption services. Due to small sample size, a bootstrap technique was again performed on the data and confidence intervals were calculated (Scholz, 2007). As distribution of the data was non-normal, a Mann Whitney U-test was used to test for differences in scores between the 'high' and 'low' adoption groups.

All analyses were conducted using SPSS (Statistical Package for Social Sciences, Version 17, SPSS Inc, Illinois, USA). For all analyses, $p<.05$ was considered statistically significant.

\section{ETHICS APPROVAL}

Full ethical approval for this project was obtained from the University of Manchester Research Ethics Committee (AJ/ethics/0805/13). 


\section{RESULTS}

\section{Survey returns and participants}

In total 462 survey packs were administered across 36 sites at each time-point (response rate of $34 \%$ at baseline; $15 \%$ at six months). Fifty participants returned surveys at both time points. Four sites returned no surveys: in three of these only one person was using the CSNAT intervention and the other site also returned incomplete or no monthly data. The characteristics of respondents at baseline are presented in Table 1. Most respondents were nurses $(71 \%)$, of which $47 \%$ were clinical nurse specialists (CNSs).

\section{[INSERT TABLE 1]}

\section{Staff attitudes to the CSNAT intervention}

Aggregate scores for the 'ATI' questionnaire at each time-point for 'high' and' low' adoption services are presented in Table 2 - see supporting information. Services were similarly positive towards the CSNAT intervention pre-implementation. Overall, attitudes to the CSNAT became less positive within 'low' adoption services and more positive within 'high' adoption services over time. Individual practitioners within 'high' adoption services, showed a significant increase in how appropriate they felt the CSNAT intervention was to use within their practice $(p=.035)$. However, a significant decrease was observed in how valuable they felt it was to their service ( $p=.046)$. Individual practitioners within 'low' adoption services showed a significant decrease in perceptions of how acceptable, appropriate, beneficial and achievable use of the CSNAT intervention was, how valuable they felt it was to both their practice and service, and how motivated they were to use the CSNAT intervention in their practice and service (all $p<.05$ ). 
A sub-analysis investigated whether practitioners who returned a survey at both time-points differed from those who returned a survey at baseline only. Those who returned both surveys were more likely to be internal facilitator (IF) $(p=.004)$. They also scored higher on motivation and perceived achievability regarding using the CSNAT in their practice $(p=.008$ and $p=.018$, respectively) and higher on the 'space' concept of the ACT ( $p=.024)$, which included having 'adequate space to provide client care' and 'private space' for confidential discussions about a client/client care.

\section{Service characteristics and organisational context for 'high' and 'low' adopters of the CSNAT intervention}

Table 3 presents an overview of service characteristics for 'high' and 'low' adoption services at baseline. Results indicate that day services/day care/day therapy were more likely to be high adopters, followed by hospice at home; CNS teams were more likely to be low adopters. 'High' adoption services also had a significantly larger proportion of internal facilitators in relation to total number of staff within the service.

[INSERT TABLE 3]

Table 4 presents aggregate ACT scores for organisational context for 'high' and 'low' adoption services at baseline. 'High' adoption services scored significantly higher on the ‘informal interactions' concept than 'low' adoption services $(p=.038)$. 'High' adoption services also had a higher score for the 'formal interactions' concept, however this difference did not reach significance $(p=.053)$.

[INSERT TABLE 4]

\section{DISCUSSION}


Study findings highlight the importance of assessing organisational context when implementing an evidence-based complex intervention and having a plan in place to ensure practitioners remain motivated to use the new intervention. Staff attitudes in both 'high' and 'low' adoption services were positive pre-implementation indicating that practitioners were receptive to the CSNAT intervention. However, by six months, attitudes in 'low' adoption services had deteriorated and become more negative than in 'high' adoption services. In contrast, attitudes to the intervention, if anything, became more positive within 'high' adoption services, particularly how appropriate they felt use of the CSNAT intervention was within their service. One exception was how valuable practitioners in the 'high' adoption group felt use of the CSNAT intervention was to their service, which decreased significantly over time. One possible explanation for this is that the CSNAT intervention was not yet embedded into practice and used more widely within the service and therefore practitioners were unsure of its value in the longer-term.

Most 'low' adoption services were clinical nurse specialist (CNS) teams, many of whom may have several weeks between patient visits and therefore may have less opportunity for assessment and follow-up of carers. In contrast, most 'high' adopters were day therapy/services and hospice at home teams. Hospice at home teams tend to make more regular/longer visits to patients' homes. Day therapy/services' patients typically attend a hospice programme over several weeks during which repeated contact with carers may be more easily arranged. Diffusion of Innovation Theory highlights the importance of 'triability': innovations which users can more easily try out tend to be adopted more easily (Rogers, 1995). If CNS teams were not seeing carers regularly and using the intervention, they may have been unable to see its benefits and levels of motivation may have subsequently decreased. CNSs are also experienced communicators and may have felt the person-centred 
approach of the CSNAT intervention would not have added benefits for their practice. Similar concerns from CNS teams has also been reported in relation to implementation of a person-centred tool for patients; the Holistic Needs Assessment Tool (HNA) (Richardson, Clunie, Winter et al., 2011). However, the measure of 'fidelity' of the CSNAT intervention in relation to use of its stages for assessment and follow-up was similar in both groups, indicating that whilst the 'low' adoption services group assessed a smaller proportion of carers, they were equally likely to complete the full intervention once initiated.

'High' adoption services were also characterised by a significantly higher proportion of internal facilitators (IFs) in relation to total number of staff indicating that higher levels of facilitation may have been possible within smaller teams. In contrast, it may have been more challenging for only two to three IFs to cascade training and provide support to larger teams of practitioners. For instance, they may have less opportunity to convene team members for regular discussion of how to overcome any barriers to implementation, which may lead to attitudes to the intervention becoming more negative over time. These findings are explored further in a separate qualitative paper which focuses on facilitation processes (Diffin, Ewing \& Grande, 2016).

Differences in organisational context at baseline were also observed between 'high' and 'low' adoption services. 'High' adoption services scored significantly higher on 'informal interactions' than 'low' adoption services suggesting that services that e.g. had more informal discussions with colleagues or in-house teaching sessions, had more success with implementation of the CSNAT. Organisational learning theory may help explain this finding; it proposes that individuals within an organisation learn within the social context of other learners (Argote, 2013). People are 'not passive recipients of innovations' but rather they 
seek to evaluate them and communicate about them (Greenhalgh, Robert, McFarlane et al., 2004). Therefore, informal interactions are probably important in helping with the learning process. Our findings indicate that ensuring regular discussions about the intervention may aid successful implementation of new evidence-based practice.

One limitation of the current study is the small sample size which restricted statistical analyses. One explanation for the low response rate observed is that services were not clear from the outset how many practitioners would be using the CSNAT intervention and so the number of surveys packs provided to services to administer (from which the response rate was calculated), was based on the number of practitioners within the team. It may be that only those practitioners who were actually going to be using/used the intervention, engaged with the survey. Aggregate scores were calculated for each service; however views of practitioners who responded may not be representative of the service as a whole. Some sites also had a higher proportion of practitioners responding to the survey in relation to total number of staff. Those practitioners who returned a survey at both time-points scored higher on baseline motivation to use the CSNAT and how achievable they felt the CSNAT would be in their practice. Survey responses at six months may therefore be from practitioners who were more engaged with implementation. Lastly, the implementation process was observed over a relatively short time period (six months). A longer-term study would enable examination of the longer-term sustainability of the CSNAT intervention.

Despite identified limitations, the study findings make an important contribution to the implementation literature and are of particular interest within palliative care/end-of-life care services as (i) it is one of the first to examine implementation of an intervention to identify and address support needs of carers, (ii) it is one of the first to examine implementation of a person-centred process of assessment and support and (iii) it examines implementation at 
scale, not just within a single service. The range of service types included in this study provides crucial understandings about the process of implementation. Further, a major strength is the study's prospective use of a theoretical framework to examine the implementation process. The findings also have implications for the PARIHS framework, illustrating the importance of considering individual attitudes and motivation to use new evidence-based practice. A recent revision to PARIHS (i-PARIHS) now includes a focus on 'recipients' of implementation, both individually and collectively (Harvey \& Kitson, 2016).

\section{CONCLUSIONS}

Policies and guidelines within palliative care, both nationally and internationally, need to recognise the complexity of implementing person-centred carer assessment and support in practice, both at the level of the individual practitioner and the organisation. This study clearly identifies several factors of importance including the need to have an adequate number of internal facilitators in relation to the size of the service. There also needs to be a planned strategy that helps ensure practitioners remain motivated to use the intervention and that takes into account organisational context, including the opportunity to use the intervention on a regular basis, and for interaction with other practitioners to support learning and information exchange.

\section{LINKING EVIDENCE TO ACTION}

- There needs to be recognition that implementation of person-centred assessment and support for family carers involves a change in practice.

- Pre-implementation planning is essential to create an implementation strategy tailored to meet the needs of individual services, which includes ensuring sufficient levels of facilitators and opportunities to use the intervention in practice. 
- Motivation to use the intervention and its embedding over time needs active engagement of practitioners through sharing and discussion of experiences of its use.

- The evidence presented in this paper will directly inform an implementation toolkit for the CSNAT intervention for use by palliative and end of life care services, both nationally and internationally. 
Accepted for Publication 17/05/18

\section{FUNDING ACKNOWLEDGEMENT}

We would like to thank Dimbleby Cancer Care who funded the overall project.

\section{ACKNOWLEDEGMENTS}

We would like to thank each service for providing the administrative assistance required to administer the survey packs and the practitioners who took the time to complete and return a survey pack. 


\section{REFERENCES}

1. Ambitions for Palliative and End of Life Care: A National framework for local action 2015-2020. 2015. Available from: http://www.endoflifecareambitions.org.uk

2. Aoun SM, Kristjanson LJ, Currow DC, et al. (2005). Caregiving for the terminally ill: at what cost? Palliative Medicine, 19(7), 551-555.

3. Aoun S, Deas K, Toye C, Ewing E, Grande G, Stajduhar K. (2015a). Supporting family caregivers to identify their own needs in end-of-life care: qualitative findings from a stepped wedge cluster trial. Palliative Medicine, 29(6), 508-517.

4. Aoun SM, Grande G, Howting D, Deas K, Toye C, Troeung L, et al. (2015b). The Impact of the Carer Support Needs Assessment Tool (CSNAT) in Community Palliative Care Using a Stepped Wedge Cluster Trial. PLoS ONE, 10(4), e0123012. doi:10.1371/journal.pone.0123012.

5. Argote L. Organizational learning: creating, retaining and transferring knowledge. 2nd ed. Norwell, MA: Kluwer Academic Publishers; 2013.

6. Collins A (2014) Measuring What Really Matters. Towards a Coherent Measurement System to Support Person-centred Care. Health Foundation, London.

7. Craig P, Dieppe P, Macintyre S, Michie S, Nazareth I, Petticrew N. (2008). Developing and evaluating complex interventions: The new Medical Research Council guidelines. British Medical Journal, 337, a1655.

8. Department of Health. End of Life Care Strategy: promoting high quality care for all adults at the end of life. London: Department of Health, 2008.

9. Department of Health. End of Life Care Strategy: quality markers and measures for end of life care. London: Department of Health, 2009. 
10. Diffin, J., Ewing, G., \& Grande, G. (2016). Facilitating successful implementation of a person-centred approach to carer assessment and support. (2016). BMJ Supportive and Palliative Care, 6(Supp 1), A1-A2.

11. Estrabrooks CA, Squires J, Cummings GG, Birdsell J, Norton PG. (2009).

Development and assessment of the Alberta Context Tool. BMC Health Services Research, 9, 234-246.

12. Ewing G, Brundle C, Payne S, Grande G. The Carer Support Needs Assessment Tool (CSNAT) for Use in Palliative and End-of-life Care at Home: A Validation Study. (2013a). Journal of Pain and Symptom Management, 46(3), 395-405.

13. Ewing G, Grande G. Development of a Carer Support Needs Assessment Tool (CSNAT) for end-of-life care practice at home: A qualitative study. (2013b). Palliative Medicine, 27(3), 244-256.

14. Ewing G, Austin L, Diffin J, Grande G. (2015). The Carer Support Needs Assessment Tool: A person centred approach to carer assessment and support. British Journal of Community Nursing, 20(12), 580-584.

15. Ewing G, Austin L, Grande G. The role of the Carer Support Needs Assessment Tool (CSNAT) in palliative home care: a qualitative study of practitioners' perspectives of its impact and mechanisms of action. (2016). Palliative Medicine, 30(4), 392-400.

16. Grande GE, Addington-Hall JM and Todd CJ. (1998). Place of death and access to home care services: are certain patient groups at a disadvantage? Social Science and Medicine, 47(5), 565-579.

17. Gomes B, Higginson IJ. Factors influencing death at home in terminally ill patients with cancer: systematic review. (2006). British Medical Journal, 332, 515-21. 
18. Grande GE, Austin L, Ewing G, O'Leary N, Roberts C. Assessing the impact of a Carer Support Needs Assessment (CSNAT) intervention in palliative home care: a stepped wedge cluster trial. (2017). BMJ Supportive and Palliative Care, 7, 326-334.

19. Greenhalgh, T, Robert G, MacFarlane F, Bate, P, Kyriakidou O. Diffusion of innovations in service organisations: Systematic review and recommendations. (2004). Milbank Quarterly, 82(4), 581-629.

20. Harvey G, Kitson A. PARIHS revisited: from heuristic to integrated framework for the successful implementation of knowledge into practice. (2016). Implementation Science, $11,33$.

21. Higginson IJ, Evans CJ, Grande G, Preston N, Morgan M, McCrone P, et al. Evaluating complex interventions in End of Life Care: the MORECare Statement on good practice generated by a synthesis of transparent expert consultations and systematic reviews. (2013). BMC Medicine, 11, 111.

22. Hudson, P. Positive aspects and challenges associated with caring for a dying relative at home. International Journal of Palliative Nursing, 10(2), 58-65.

23. Kitson A, Harvey G, McCormack B. Enabling the implementation of evidence based practice: a conceptual framework. (1998). Quality in Health Care, 7(3), 149-158.

24. Moore GF, Audrey S, Barker M, Bond L, Bonell C, Hardeman W et al. Process evaluation of complex interventions: Medical Research Council guidance. (2015). British Medical Journal, 350, h1258.

25. National Institute for Clinical Excellence (NICE). Guidance on cancer services. Improving supportive and palliative care for adults with cancer. The manual. London: NICE, 2004. 
26. NHS Scotland. (2008). Living Well and Dying Well: a national action plan for palliative and end of life care in Scotland. Retrieved from: http://www.gov.scot/resource/doc/239823/0066155.pdf

27. Proctar E, Silmere H, Raghavan R, Hovmand P, Aarons G, Bunger A et al. Outcomes for Implementation Research: Conceptual Distinctions, Measurement Challenges, and Research Agenda. (2011). Administration in Policy and Mental Health, 38, 65-76.

28. Rogers, E. M. (1995). Diffusion of innovations (4th ed.). New York: The Free Press.

29. Richardson A, Clunie M, Winter J, Gabriel J, Stanley S, Morris C et al. (2011). Finding the time for teams to undertake holistic needs assessment. Retrieved from: http://webarchive.nationalarchives.gov.uk/20130513211237/http:/www.ncat.nhs.uk/o ur-work/living-beyond-cancer/holistic-needs-assessment\#

30. Rowland, C., Hanratty, B., Pilling, M., van den Berg., Grande, G. The contributions of family care-givers at end of life: A national post-bereavement census survey of cancer carers' hours of care and expenditures. (2017). Palliative Medicine, 31(4), 346-355.

31. Rycroft-Malone J, Kitson A, Harvey G, McCormack B, Seers K, Titchen A, Estabrookes C. Ingredients for change: revisiting a conceptual framework. (2002). Quality and Safety in Healthcare, 11(2), 174-180.

32. Scholz FW. (2007). The bootstrap small sample properties. University of Washington, Seattle, WA.

33. Schulz R and Beach SR. Caregiving as a risk factor for mortality - the caregiver health effects study. (1999). JAMA, 282(23), 2215-2219.

34. Squires, JE, Hutchinson, AM, Hayduk L, Cranley L, Cummings G, Norton PG, \& Estabrooks, CA. (2014). Alberta Context Tool: User Manual. Knowledge Utilization 
Studies Program, Faculty of Nursing, University of Alberta, Edmonton, Canada (ISBN:978-1-55195-340-3).

35. Squires JE, Hayduk L, Huthinson AM, Mallick R, Norton PG, Cummings G, Estrabrooks CA. Reliability and validity of the Alberta Context Tool with professional nurses: Findings from a multi-study analysis. (2015). PLoS ONE, 10(6), e0127405. doi:10.1371/journal.pone.0127405

36. Stajduhar KI, Funk L, Outcalt L. (2013). Family caregiver learning- how family caregivers learn to provide care at the end of life: a qualitative secondary analysis of four datasets. Palliative Medicine, 27(7), 657-664. 
Table 1: Baseline characteristics for individual practitioners who returned a survey pack prior to implementation

\begin{tabular}{lcc} 
& $\mathrm{N}$ & $\%$ \\
\hline Role of practitioner & & \\
Clinical Nurse Specialist (CNS) & 73 & 46.5 \\
Registered Nurse (other than CNS) & 37 & 23.6 \\
Social Worker & 7 & 4.5 \\
Medical Practitioner & 3 & 1.9 \\
Other & 34 & 21.7 \\
& & \\
Role involves making home visits? (y) & 119 & 75.8 \\
& & \\
Internal facilitator? (y) & 39 & 24.8 \\
& & \\
Previously used an evidence-based tool? (y) & 45 & 28.7 \\
\hline
\end{tabular}


Table 2: Aggregate mean (SD) scores for the 'ATI' questionnaire for 'high' and 'low' adopters of the CSNAT intervention

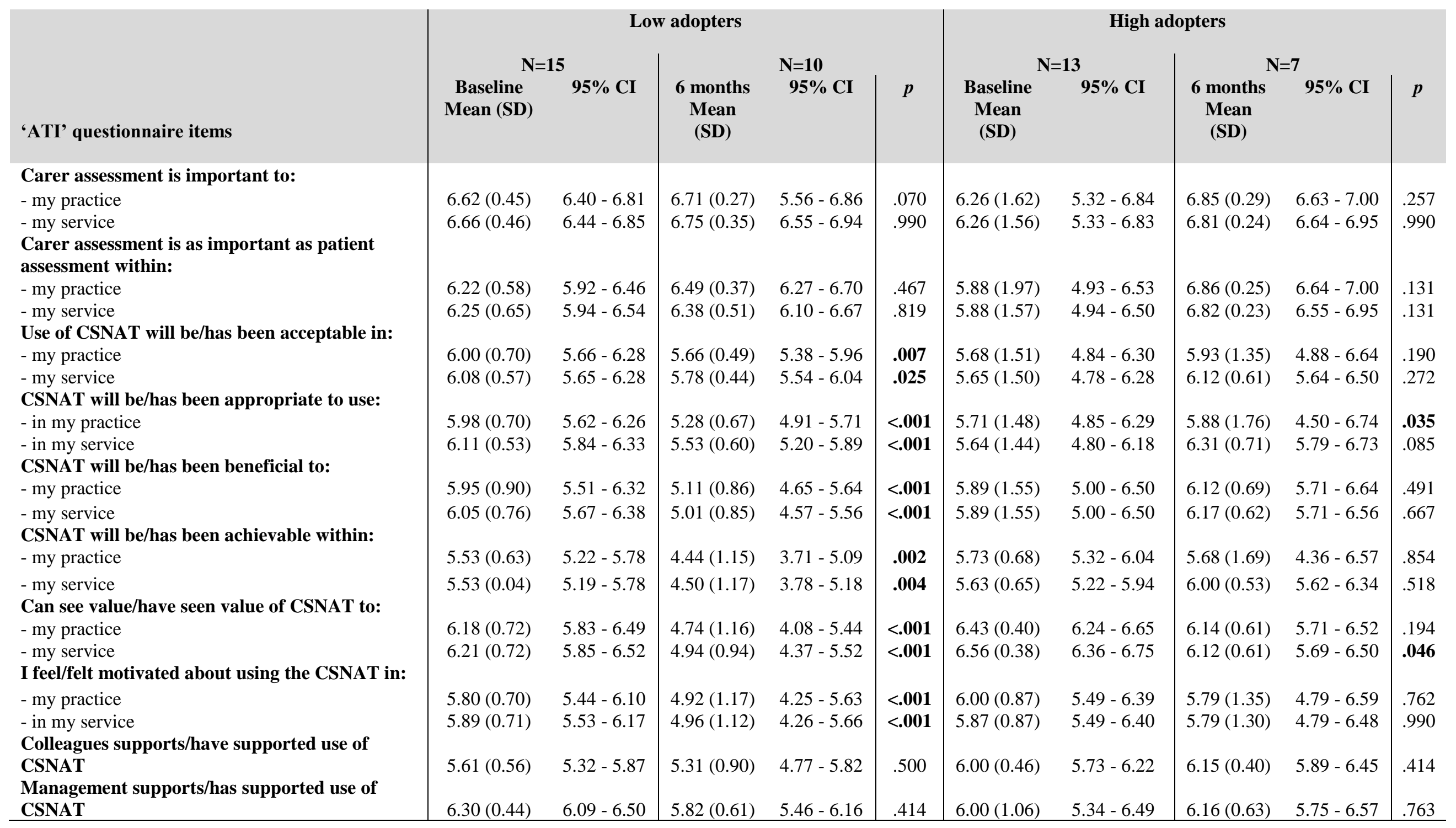

\pm level of adoption defined as the number of CSNATs completed by carers in relation to the number of new patients ** Mean (SD) and CI reflect aggregate scores for each service

$\pm p$ values relate to analysis of changes in scores over time for individual practitioners within 'high' and 'low' adoption

services who responded at each time-point (See supplemental file for individual practitioner scores at each time-point) 
Table 3: Service characteristics of 'low' and 'high' adopters of the CSNAT

Type of service

Day services/daycare/day therapy

Hospice at Home

Clinical Nurse Specialist Team

Social Work Team

Other

Number of new patients per year

$0-100$

$100-200$

200-300

300-500

$500+$

Proportion of staff using CSNAT in relation to total

number of staff: Mean \% (SD)

\section{Low Adopters \\ $\mathrm{N}=16$ \\ N \%}

Proportion of internal facilitators in relation to number of staff:

Mean \% (SD)

Effective use of the CSNAT (Proportion of action plans completed with carers in relation to the number who indicated they had support needs): Mean \% (SD)

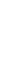

2

2

9

9

1

2

0

3

1

2

5

西

$\begin{array}{cc}0 & 0 \\ 3 & 20.0 \\ 1 & 6.7 \\ 2 & 13.3 \\ 5 & 33.3\end{array}$

12.5

12.5

56.3

6.3

12.5

12.5

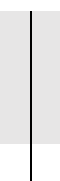

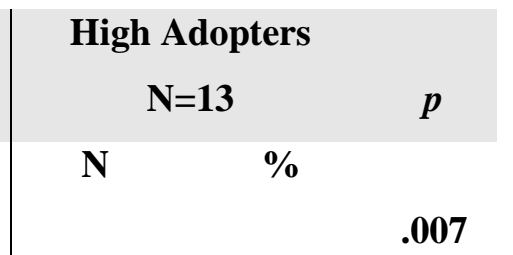

7

53.8

38.5

0

0

$\begin{array}{ll}1 & 7.7\end{array}$

.313

3

23.1

$4 \quad 30.8$

$1 \quad 7.7$

$1 \quad 7.7$

$2 \quad 15.4$

$75.9(39.40)$

.095

$32.40(25.36)$

.011

$14.2(7.90)$

$32.40(25.36)$

$79.1(27.62)$

\pm level of adoption defined as the number of CSNATs completed by carers in relation to the number of new patients 
Accepted for Publication 17/05/18

Table 4: Aggregate scores for the Alberta Context Tool for high and low adopters of the CSNAT intervention

\section{Low adopters $\mathrm{N}=15 \quad$ High adopters $\mathrm{N}=12$}

ACT Concepts

Max Mean (SD) $\quad 95 \%$ CI $\quad$ Mean (SD) $\quad 95 \%$ CI $\quad p$

score

\begin{tabular}{lcccccc} 
Leadership & 6 & $4.06(.42)$ & $3.84,4.25$ & $3.90(.62)$ & $3.56,4.27$ & .272 \\
Culture & 6 & $4.14(.46)$ & $3.91,4.34$ & $3.93(.35)$ & $3.73,4.10$ & .059 \\
Feedback & 6 & $3.44(.55)$ & $3.19,3.73$ & $3.13(.88)$ & $2.58,3.58$ & .905 \\
Formal interactions & 4 & $1.09(.52)$ & $0.85,1.36$ & $1.63(.94)$ & $1.14,2.16$ & .053 \\
Informal interactions & 9 & $3.38(1.30)$ & $2.78,4.02$ & $4.14(.80)$ & $3.71,4.59$ & $\mathbf{. 0 3 8}$ \\
Connections/ social & 6 & $4.43(.31)$ & $4.27,4.58$ & $4.45(.41)$ & $4.23,4.67$ & .324 \\
capital & & & & & & \\
Structural/ electronic & 11 & $5.23(.90)$ & $4.73,5.66$ & $6.22(2.37)$ & $4.81,7.60$ & .856 \\
resources & & & & & & \\
Organisational slack & & & & & & \\
$\quad-\quad$ Staff & 5 & $3.36(.77)$ & $2.96,3.70$ & $2.98(0.94)$ & $2.41,3.47$ & .241 \\
$\quad$ - Space & 5 & $3.43(.74)$ & $3.07,3.79$ & $3.52(.90)$ & $2.98,4.00$ & .815 \\
$\quad$ Time & 4 & $3.43(.39)$ & $3.24,3.62$ & $3.56(.44)$ & $3.32,3.85$ & .449 \\
\hline
\end{tabular}

\pm Dimensions in bold are calculated as mean values, those in normal font as the sum of re-scored items (scoring in accord with ACT scoring guidelines)

\pm level of adoption defined as the number of CSNATs completed by carers in relation to the number of new patients 
Stage 1. Introduction of CSNAT

Practitioner introduces the CSNAT tool to a carer

Stage 5. Shared review

The shared action plan is reviewed at another point in time to determine if carer's support needs have changed

Stage 4. Shared Action Plan Together, the practitioner and carer agree on what supportive input would be helpful
Stage 2. Carer consideration of needs Carer considers their individual support needs in relation to each domain and prioritises those most important to them at that point in time

Stage 3. Assessment conversation Carer and practitioner have a conversation to determine what the carer's individual support needs are in relation to the domains they have prioritised

Figure 1: The five stages of The Carer Support Needs Assessment Tool (CSNAT) Intervention 
Supplemental File 1: Mean (SD) scores for the 'ATI' questionnaire for individual practitioners within 'high' and 'low' adoption services

\begin{tabular}{|c|c|c|c|c|c|c|c|c|c|c|}
\hline \multirow[b]{3}{*}{ 'ATI' questionnaire items } & \multicolumn{5}{|c|}{ Low adopters } & \multicolumn{5}{|c|}{ High adopters } \\
\hline & \multicolumn{2}{|c|}{$\mathrm{N}=97$} & \multicolumn{3}{|c|}{$\mathrm{N}=42$} & \multicolumn{2}{|c|}{$\mathrm{N}=43$} & \multicolumn{2}{|c|}{$\mathbf{N}=\mathbf{2 0}$} & \multirow[b]{2}{*}{$p$} \\
\hline & $\begin{array}{c}\text { Baseline } \\
\text { Mean (SD) }\end{array}$ & $95 \% \mathrm{CI}$ & $\begin{array}{c}6 \text { months } \\
\text { Mean } \\
\text { (SD) }\end{array}$ & $95 \% \mathrm{CI}$ & $p$ & $\begin{array}{c}\text { Baseline } \\
\text { Mean } \\
\text { (SD) }\end{array}$ & $95 \% \mathrm{CI}$ & $\begin{array}{l}6 \text { months } \\
\text { Mean } \\
\text { (SD) }\end{array}$ & $95 \% \mathrm{CI}$ & \\
\hline Carer assessment is important to: & & & & & & & & & & \\
\hline - my practice & $6.59(0.87)$ & $6.41-6.75$ & $6.59(1.01)$ & $6.23-6.84$ & .070 & $6.40(1.41)$ & $5.90-6.76$ & $6.75(0.55)$ & $6.50-6.95$ & .257 \\
\hline - my service & $6.65(0.80)$ & $6.49-6.79$ & $6.69(0.97)$ & $6.37-6.91$ & .990 & $6.37(1.38)$ & $5.87-6.74$ & $6.75(0.55)$ & $6.50-6.95$ & .990 \\
\hline $\begin{array}{l}\text { Carer assessment is as important as patient } \\
\text { assessment within: }\end{array}$ & & & & & & & & & & \\
\hline - my practice & $6.21(1.00)$ & $6.62-6.41$ & $6.83(1.08)$ & $6.00-6.66$ & .467 & $6.16(1.26)$ & $5.71-6.50$ & $6.80(0.41)$ & $6.60-6.95$ & .131 \\
\hline - my service & $6.27(0.93)$ & $6.08-6.44$ & $6.33(1.05)$ & $5.98-6.61$ & .819 & $6.13(1.26)$ & $5.68-6.47$ & $6.80(0.52)$ & $6.55-7.00$ & .131 \\
\hline Use of CSNAT will be/has been acceptable in: & & & & & & & & & & \\
\hline - my practice & $6.12(0.94)$ & $5.94-6.30$ & $5.67(1.24)$ & $5.29-6.05$ & .007 & $6.10(1.11)$ & $5.71-6.42$ & $6.10(1.07)$ & $5.60-6.50$ & .190 \\
\hline - my service & $6.13(0.92)$ & $5.97-6.32$ & $5.79(1.02)$ & $5.48-6.09$ & .025 & $6.05(1.11)$ & $5.66-6.37$ & $6.15(0.74)$ & $5.85-6.45$ & .272 \\
\hline CSNAT will be/has been appropriate to use: & & & & & & & & & & \\
\hline - in my practice & $6.06(1.00)$ & $5.87-6.26$ & $5.30(1.37)$ & $4.86-5.70$ & $<.001$ & $6.00(1.20)$ & $5.58-6.34$ & $6.15(1.18)$ & $5.55-6.60$ & .035 \\
\hline - in my service & $6.19(0.91)$ & $6.02-6.36$ & $5.50(1.09)$ & $5.16-5.81$ & $<.001$ & $6.00(1.20)$ & $5.58-6.34$ & $6.30(0.73)$ & $6.00-6.60$ & .085 \\
\hline CSNAT will be/has been beneficial to: & & & & & & & & & & \\
\hline - my practice & $6.00(1.16)$ & $5.76-6.21$ & $5.07(1.53)$ & $4.56-5.53$ & $<.001$ & $6.13(1.17)$ & $5.71-6.45$ & $6.15(0.93)$ & $5.75-6.50$ & .491 \\
\hline $\begin{array}{l}\text { - my service } \\
\text { CSNAT will be/has been achievable within: }\end{array}$ & $6.12(1.02)$ & $5.92-6.31$ & $5.09(1.43)$ & $4.65-5.52$ & $<.001$ & $6.13(1.17)$ & $5.71-6.45$ & $6.25(0.79)$ & $5.90-6.55$ & .667 \\
\hline - my practice & $5.59(1.01)$ & $5.40-5.77$ & $4.71(1.42)$ & $4.24-5.12$ & .002 & $6.00(0.93)$ & $5.71-6.26$ & $5.95(1.27)$ & $5.35-6.45$ & .854 \\
\hline - my service & $5.57(1.00)$ & $5.38-5.77$ & $4.80(1.35)$ & $4.39-5.21$ & .004 & $5.87(0.93)$ & $5.55-6.16$ & $6.10(0.79)$ & $5.75-6.40$ & .518 \\
\hline $\begin{array}{l}\text { Can see value/have seen value of CSNAT to: } \\
\text { - my practice }\end{array}$ & $6.16(1.03)$ & $5.97-6.36$ & $4.83(1.74)$ & $4.30-5.33$ & $<.001$ & $6.50(0.65)$ & $6.29-6.68$ & $6.15(0.93)$ & $5.75-6.55$ & .194 \\
\hline $\begin{array}{l}\text { - my service } \\
\text { I feel/felt motivated about using the CSNAT in: }\end{array}$ & $6.23(0.99)$ & $6.03-6.42$ & $5.02(1.41)$ & $4.58-5.43$ & $<.001$ & $6.58(0.50)$ & $6.42-6.74$ & $6.10(0.85)$ & $5.75-6.45$ & .046 \\
\hline - my practice & $5.95(1.10)$ & $5.61-6.07$ & $4.86(1.80)$ & $4.28-5.40$ & $<.001$ & $6.05(1.04)$ & $5.71-6.37$ & $5.85(1.22)$ & $5.30-6.35$ & .762 \\
\hline - in my service & $5.95(1.10)$ & $5.74-6.17$ & $5.02(1.52)$ & $4.56-5.50$ & $<.001$ & $6.03(0.91)$ & $5.74-6.32$ & $5.95(1.05)$ & $5.45-6.35$ & .990 \\
\hline $\begin{array}{l}\text { Colleagues supports/have supported use of } \\
\text { CSNAT }\end{array}$ & $5.62(1.01)$ & $5.40-5.81$ & $5.52(1.19)$ & $5.14-5.88$ & .500 & $6.08(0.71)$ & $5.87-6.31$ & $6.15(0.67)$ & $5.85-6.45$ & .414 \\
\hline $\begin{array}{l}\text { Management supports/has supported use of } \\
\text { CSNAT }\end{array}$ & $6.34(0.78)$ & $6.17-6.50$ & $6.10(0.91)$ & $5.81-6.36$ & .414 & $6.21(0.87)$ & $5.89-6.45$ & $6.00(0.97)$ & $5.55-6.40$ & .763 \\
\hline
\end{tabular}

tlevel of adoption defined as the number of CSNATs completed by carers in relation to the number of new patients

** Mean (SD) and CI reflect scores for individual practitioners within each service

$\pm p$ values relate to analysis of changes in scores over time for individual practitioners within 'high' and 'low' adoption

who responded at both time-points 


\section{Supplemental File 2: Implementation strategy for the CSNAT intervention}

\begin{tabular}{|c|c|}
\hline \multicolumn{2}{|r|}{ Implementation strategy for the CSNAT intervention } \\
\hline $\begin{array}{l}\text { Selection of internal } \\
\text { facilitators }\end{array}$ & $\begin{array}{l}\text { Each service selects } 2-3 \text { practitioners to take on the role of internal facilitator (IF); } \\
\text { referred to within their service as 'CSNAT Champions'. One practitioner takes on } \\
\text { the role of the 'lead' IF, acting as the main point of contact between the service } \\
\text { and CSNAT team (external facilitators; EFs). }\end{array}$ \\
\hline $\begin{array}{l}\text { Training for internal } \\
\text { facilitators }\end{array}$ & $\begin{array}{l}\text { All IFs attend a 'CSNAT training day' hosted by the CSNAT team (EFs). } \\
\text { Training includes a detailed description of the CSNAT intervention and the } \\
\text { following activities: } \\
\text { - Reflection on their organisation's ethos or mission statement. } \\
\text { - Considering how services currently became aware of carer support needs. } \\
\text { - Making an 'implementation plan' for their service. } \\
\text { IFs are provided with a 'CSNAT training' toolkit. This includes all information } \\
\text { covered at the training day and hints and tips on how to implement the CSNAT } \\
\text { intervention in practice. A power-point presentation and accompanying notes are } \\
\text { also supplied to enable IFs to provide training to their colleagues. }\end{array}$ \\
\hline $\begin{array}{l}\text { Key responsibilities of } \\
\text { internal facilitators within } \\
\text { their service }\end{array}$ & $\begin{array}{l}\text { - } \quad \text { Cascading training on the CSNAT intervention to their colleagues. } \\
\text { - } \text { Acting as a positive role model and supporting their colleagues on how to } \\
\text { use the CSNAT intervention to support best practice (e.g. by sharing their } \\
\text { experiences of using the intervention). } \\
\text { - } \quad \text { Holding regular discussions with colleagues on issues related to using the } \\
\text { intervention in practice (both formally and informally). } \\
\text { - } \quad \text { Directing colleagues to sources of support (e.g. training materials supplied } \\
\text { at the 'CSNAT training day'). } \\
\text { - Participation in monthly one-hour teleconferences with the CSNAT team } \\
\text { (EFs) and lead IFs from other sites for the purposes of peer support. }\end{array}$ \\
\hline
\end{tabular}

